\title{
BRANQUITUDE E EPISTEMOLOGIA ANTIRRACISTA: POR UMA LINGUÍSTICA APLICADA EFETIVAMENTE CRÍTICA
}

\author{
WHITENESS AND ANTIRACIST EPISTEMOLOGY: \\ FOR A RATHER CRITICAL APPLIED LINGUISTICS
}

Thais Regina Santos Borges*

\section{RESUMO}

O objetivo deste trabalho é propor uma reflexão crítica acerca do papel da branquitude na produção de saberes acadêmicos na Linguística Aplicada Crítica, consonante com seu horizonte de justiça social, ao se ocupar de fenômenos sociais em que a linguagem enquanto sociossemiose tem papel fundamental. Apoiada no paradigma simultaneamente decolonial (CURIEL, 2017) e interseccional (COLLINS, 1990), defendo sua vocação necessariamente antirracista, no contexto dos embates contrahegemônicos de uma academia entendida como instanciação do mundo "cubo-branco" (KILOMBA, 2019), para configurar a área como efetivamente crítica, a partir da consolidação de uma epistemologia antirracista que atravesse o campo. Nesse sentido, destaco a necessidade de escrutínio da branquitude enquanto conjunto de práticas sociais (CONCEIÇÃO, 2020), refletindo sobre performances raciais (MELO, 2018) da branquitude crítica (CARDOSO, 2017) na academia. Tendo como pressuposto o caráter crítico-reflexivo da pesquisa em si (DE FINA, 2015), destaco a pertinência da escuta ativa e de processos de autoescuta, em que há a possibilidade de "se ouvir escutando" (SOUZA, 2011), a fim de driblar a transparência de ideologias racistas da branquitude performadas discursivamente por analistas brancos, brancas e branques em seu silêncio performativo de racismo (BENTO, 2002). Trazendo a ideia de transformação social para dentro do próprio campo, proponho pensar o "estudo" (HARNEY; MOTEN, 2013), uma forma de oposição à produção de conhecimento, que é expoente de um fazer acadêmico colonial e colonizado, em consonância com a performatividade afetiva do "sentir crítico", para articular novos modos de ser, estar, agir e sentir no/ com o mundo (BORGES, 2017a).

Palavras-chave: epistemologia antirracista, branquitude, decolonialidade, interseccionalidade, linguística aplicada crítica.

\section{ABSTRACT}

The aim of this paper is to propose a critical reflection on the role of whiteness in the production of academic knowledge in Critical Applied Linguistics, in line with its horizon of social justice when dealing with social phenomena in which language as a sociosemiosis plays a fundamental role. Simultaneously decolonial (CURIEL, 2017) and intersectional (COLLINS, 1990), I defend its consequently antiracist drive, within counter-hegemonic struggles in Academia as the instantiation of the "white-cube" (KILOMBA, 2019) in order to make the area rather critical by the consolidation of an antiracist epistemology across the field. In this sense, I highlight the need to scrutinize whiteness as a set of social practices (CONCEIÇÃO, 2020), reflecting on racial performances (MELO, 2018) of critical whiteness (CARDOSO, 2017) in academia. Assuming the critical-reflexive character of the research itself (DE FINA, 2015), I emphasize the relevance of active listening and processes of self-listening, where there is the possibility of "hearing yourself listening" (SOUZA, 2011), in order to bypass the transparency of racist ideologies of whiteness performed discursively by white analysts in their silence which is performative of racism (BENTO, 2002). Turning the idea of social transformation to the field itself, I propose to think of "study" (HARNEY; MOTEN, 2013), a way to oppose knowledge production as an exponent of a colonial and colonized academic doing, thinking also of the affective performativity of "critical feeling" to articulate new ways of being, acting and feeling in/ with the world (BORGES, 2017a).

Keywords: antiracist epistemology, whiteness, decoloniality, intersectionality, critical applied linguistics

\section{INTRODUÇÃO}

Epistemologia é relação de poder porque epistemologia é performativo de ontologia (LIMA, 2018). Falar sobre epistemologia antirracista implica, portanto, necessariamente repensar quem, o quê e a quem serve a produção de conhecimento, mais ou menos estruturada, para fins de entendimento, reflexão e teorização acerca dos fenômenos que nos cercam. Dentro da academia, essa produção não é abstrata, não se dá em um vácuo; ela é feita por pessoas, por sujeitos cujas práticas discursivas e sociais, identitárias inclusive, são inexoravelmente atravessadas por sistemas de poder variados que interagem interseccionalmente na matriz de dominação (COLLINS, 1990). Assim, o poder hegemônico exercido ali, de forma relacional, complexa e contextualizada, configura também práticas contrahegemônicas de resistência, dentro e através dos domínios de poder disciplinar, cultural, estrutural e interpessoal, para fins de justiça social, princípios da interseccionalidade como prática investigativa e práxis (COLLINS, BILGE, 2016), que abordo neste trabalho.

\footnotetext{
* Pontifícia Universidade Católica do Rio de Janeiro (PUC-Rio, Rio de Janeiro, RJ, Brasil. thaisrsborges@gmail.com
} Orcid: https://orcid.org/0000-0002-2595-5618 
Mantendo isso em mente, como parte do fazer acadêmico, o estudo praticado nos confins dos abaixo-comuns da universidade, conforme proposto por Stefano Harney e Fred Moten (2013), seria uma forma possível de contraposição ao modus operandi institucional e ao modus vivendi institucionalizado, que cerceiam ali a criatividade e a asserção de diferentes modos de ser, estar, agir e sentir no/ com o mundo (BORGES, 2017a). Ou seja, as práticas identitárias, as interações, as ações/reações/vivências e as performances afetivas, respectivamente, que se dão em meio às nossas construções e co-construções de mundo no contato com outros sujeitos, outros mundos (FREIRE, 1995), ali e em outros espaços. Chamado de estudo, esse movimento, essa prática com um fim em si mesma, sem ânsia de legitimação ou crédito, se dá, acima de tudo, à revelia do sistema hegemônico, ainda que dentro, "em quebra" (HALBERSTAM, 2013, p.13), como explico em breve.

No domínio acadêmico, essa postura é essencial, principalmente a partir do pressuposto de que a universidade é expoente direto da indissociabilidade tripartite da modernidade-colonialidade-capitalismo (CURIEL, 2017), cuja mola motriz é o advento do racismo como tecnologia de necropoder (MBEMBE, 2018), ainda que palco de embates contra-hegemônicos. Sob essa ótica, a academia é vista como um espaço de colonialidade de poder/ser/ saber (CURIEL, 2017) e uma instanciação performativa do mundo cubo-branco a que Grada Kilomba se refere para falar desse universo criado pela branquitude, em sua memorável exposição Desobediências Poéticas, no Brasil em 2019. Na obra da artista, bem como nas relações raciais contemporâneas, a branquitude, na performatividade de suas cosmovisões predatórias e de suas subjetividades perversas/pervertidas, projeta suas particularidades minoritárias como paradoxalmente universais. É sob essa ótica que fica nítida a urgência de se pensar no fazer acadêmico como também contingenciado pelos regimes de poder da branquitude, priorizando um olhar decolonial, e racializante, portanto, para as práticas investigativas e a práxis, junto à interseccionalidade, como abordo em breve.

Nesse sentido, é necessário escrutinar como opera a branquitude em suas várias dimensões: social, cultural, política, discursiva, identitária, sociossemiótica, ideológica, etc. visando ao desengajamento das práticas opressoras da performatividade racial branca que beneficiam pessoas brancas estrutural, institucional e interpessoalmente na forma de privilégios configurados por práticas racistas, ainda que não intencionalmente. Nessa lógica, é preciso refletir acerca da impossibilidade ontológica do sujeito branco subversivo a partir de performances raciais (MELO, 2019) da branquitude crítica (CARDOSO, 2020), em especial o silêncio performativo de racismo (BENTO, 2002). Paradoxalmente, é preciso ainda admitir a possibilidade de subversão via escuta ativa (NASCIMENTO, 2019) e auto-escuta, em processos de (auto)letramento crítico, conforme descrito por Menezes de Souza (2011), levando em consideração o posicionamento social de acadêmicas, acadêmicos, acadêmices branques, brancos e brancas na luta antirracista. Levar isso em conta significa, então, repensar as co-construções discursivas que moldam a branquitude nos encontros de suas pesquisas, entendendo-as em si mesmas como performativas (DE FINA, 2015), impulsionando a adoção de hábitos mais frutíferos para toda a área. Refletir sobre isso é urgente para que, abandonada a impossibilidade ética de dar voz ao outro, a branquitude crítica acadêmica que se entende antirracista possa ir além do posicionamento intelectualmente preguiçoso ou ingênuo de tão somente ouvir o Outro, passando a se questionar, escrutinando suas leituras de mundo ao "se ouvir escutando" (MENEZES DE SOUZA, 2011, p.132).

O combate à desigualdade racial é objetivo intrínseco aos estudos que se dizem críticos, o que torna a conversa que nutro aqui absolutamente inadiável. Mais ainda, visando à promoção do antirracismo, é preciso entendê-lo como "um fazendo", algo "processual", que "não é um objetivo, um lugar a que se chega y do qual não se sai mais", mas, sim, aquilo que "não termina enquanto houver racismo" (NASCIMENTO, 2019, on-line), que pode e deve se desenvolver em processos de estudo, aos moldes de Harney e Moten (2013), e pelo amadurecimento de um sentir crítico, conforme proposto por Borges (2017a, 2017b). Intimamente ligado à performatividade afetiva de processos (auto) críticos e (auto)reflexivos, o sentir crítico pode ser compreendido como um devir de sensibilidade que nos mobiliza em performances afetivas em prol de justiça social e diz respeito ao valor pedagógico das construções performativas do afeto para subversão micropolítica contra-hegemônica (BORGES, 2017b). Esse modo de sentir criticamente é fomentado a partir dos entendimentos traçados em nossas leituras de mundo, construídas na interação social, em processos que visam a conscientização crítica (FREIRE, 1995) e uma revisão constante dos nossos modos de ser, estar, agir e sentir no/ com o mundo (BORGES, 2017a). A performatividade afetiva que esse devir abarca engloba o pensamento crítico e a ação política criticamente orientada, mas foca principalmente no papel do afeto, sempre com um horizonte de justiça social, em um processo que pode, no fim das contas, ajudar a mobilizar micropoliticamente a criação coletiva de novos mundos possíveis, já em andamento nos abaixo-comuns (MOTEN, HARNEY, 2018), como explico na última sessão deste trabalho. 
A urgência de repensar o papel da branquitude crítica, aquela que não expressa seu racismo abertamente (CARDOSO, 2017), maior parte do grupo social branco e da academia, em especial nas áreas que se dizem críticas, repousa na necessidade de assumirmos posições mais ativas. Assim, cabe propor que trabalhemos para estabelecer diálogos epistemológicos e interpessoais tão francos e justos quanto conflituosos. É preciso que a academia branca enfrente a si mesma e seus privilégios como um dos grandes empecilhos para a equidade racial, se almejamos justiça social também no domínio epistemológico. Por isso, defendo a importância do escrutínio dos regimes da branquitude cisheteronormativa moderna-colonial-capitalista (CURIEL, 2017) também na Linguística Aplicada Indisciplinar (MOITA LOPES et al, 2006, 2013) e Crítica (PENNYCOOK, 2008). Nutrindo um olhar simultaneamente interseccional e decolonial, defendo a conformação de uma epistemologia antirracista que atravesse o campo a fim de desenhá-lo como obstinadamente crítico.

Proponho, assim, muito estudo (HARNEY, 2018) e a adoção de uma postura (auto)crítica e (auto)reflexiva em processos que fomentem nosso sentir crítico (BORGES, 2017a, 2017b), conforme desenvolvo a seguir, a começar pela premissa antirracista da decolonialidade e da interseccionalidade como práticas investigativas e práxis.

\section{DECOLONIALIDADE, INTERSECCIONALIDADE E EPISTEMOLOGIA ANTIRRACISTA: SITUANDO A BRANQUITUDE}

A importância das lentes decolonial e interseccional para a promoção de uma epistemologia antirracista está na centralidade da raça, do racismo e dos regimes da branquitude cisheteronormativa moderna-colonial-capitalista (CURIEL, 2017) embutida nessas duas perspectivas. Basicamente, se um trabalho se diz orientado pelo viés da decolonialidade e/ou da interseccionalidade como prática investigativa e práxis, sua análise precisa ter na raça um construto relevante para articulação de sentidos. A não observação de questões raciais, nesse contexto, significa uma incoerência que denuncia a operacionalização do racismo e, portanto, da branquitude, no contexto do fazer epistemológico proposto.

O termo colonialidade se refere ao lastro que permanece no processo de ocidentalização do mundo após o advento do colonialismo e a permanência de suas lógicas nas estruturas, instituições e sujeitos, em dinâmicas atreladas às macro-estruturas (poder), às subjetividades (ser) e às epistemologias (saber). Segundo Ochy Curiel (2017), a questão preponderante é que ao fim do colonialismo como eixo histórico nada mudou em relação à modernidade ocidental, à divisão internacional do trabalho ou à hierarquização racial, de gênero e de sexualidades, apenas houve uma extensão desse fenômeno, uma espécie de colonialismo moderno, que é a colonialidade global contemporânea. Para a antropóloga dominicana, a colonialidade não admite o fim do colonialismo porque há um colonialismo interno, geopolítico, mais vivo do que nunca, exemplificado no massacre de comunidades autóctones para fins de extrativismo. No entanto, foca na colonialidade, que é uma espécie de sequela desse eixo colonial, a partir do qual se pode pensar as relações de poder mundial atualmente. Nessa linha, a colonialidade de poder é extensão do colonialismo e se apoia na hierarquização feita a partir da raça como invenção determinante na organização das dinâmicas econômicas do sistema-mundo eurocêntrico pela operacionalização do racismo, que permanece no papel de estruturador de todas as relações sociais, econômicas e culturais (QUIJANO, 2010). Entende-se que o colonialismo é inerente e essencial à modernização da Europa e, consequentemente, à constituição da farsa do humanismo europeu, marca maior da subjetividade moderna ocidental. Esvaziada a categoria bumanouniversal, ao pintar esse (pseudo) bumano de branco, fica denunciado que é a terceirização da necropolítica às colônias que permite que europeus construam seus modos de viver pautados nos construtos racistas da liberdade, da fraternidade e da igualdade desde que para os seus.

Em contrapartida, a decolonialidade consiste em usar o conhecimento, científico ou não, acerca da colonialidade para desconstruí-la, situadamente, a partir de construções teóricas e práticas suleadas, ou seja, orientadas pelas epistemologias do Sul (SOUSA SANTOS, MENESES, 2010), que questionam a hegemonia das epistemologias brancocêntricas do Norte global. Enquanto área, é afinada com a Linguística Aplicada Indisciplinar e Crítica por sua vocação para a disrupção e a desconstrução, traduzidas em tentativas de subversão do status quo firmado nos princípios da modernidade que definem bumanidade. À essa luz, não só questionam a modernidade, como disputam essa humanidade constituída na hierarquização a partir da ficção da raça, expoente do racismo como tecnologia do necropoder colonial (MBEMBE, 2018). A raça não é causa do racismo, mas consequência. Com base nisso, para o campo dos estudos decoloniais, é no horror da instituição do colonialismo no chamado novo mundo, que de novo possuía 
somente os invasores recém-chegados e a adoção do racismo como tecnologia de poder em prol da branquitude, que nasce o sistema-mundo eurocêntrico. O encobrimento da América em 1492 (DUSSEL, 1994) constitui o serbranco-com-alma-civilizado em oposição ao não-ser-Índio-sem-alma-primitivo e sua extensão analógica posterior, o não-ser-Negro. Embuído do fardo kipliano da pecha civilizatória, o então Branco-colonizador-europeu se reencontra com a África e produz o holocausto do povo preto (CESAIRE, 1978), instaurando a desumanização visceral da pessoa negra enquanto "homem-objeto, homem-mercadoria e homem-moeda" (MBEMBE, 2018, p.14) nas práticas brancas de exploração, expropriação e extrativismo, explicando a indissociabilidade da modernidade-colonialidade-capitalismo (CURIEL, 2017), base dos regimes da branquitude cisheteronormativa de hoje.

Nessa lógica, pensar a branquitude do ponto de vista decolonial significa ler o branco-bumano como forjado racional, afetiva e ideologicamente na desumanização do outro, de modo que o branco-bumano-parâmetro nasce na hierarquização racial, ou seja, pelo racismo, a partir da instituição do colonialismo. Além disso, ao ver o branco como construto social, temos nele interesse de pesquisa para repensar o modus operandi das instituições modernas na contemporaneidade e o modus vivendi das pessoas e suas comunidades atravessadas por questões de branquitude, visando seu escrutínio e desmantelamento.

Com base nisso, o que é possível concluir sem dúvida é que o olhar decolonial deve ser, portanto, um olhar que racializa as questões e põe em xeque os regimes da branquitude. Desse modo, sua aliança à interseccionalidade como prática investigativa e práxis (COLLINS, BILGE, 2016) pode significar uma poderosa ampliação dessa lente em meio à produção de saber da universidade como instanciação desse mundo colonial e colonizado a que Grada Kilomba $(2019$, n.p.) se refere por cubo-branco.

A interseccionalidade como epistemologia deriva do feminismo negro e das várias questões levantadas pelas mulheres negras e latinas sobre o sujeito do feminismo, problematizando a necessidade de legitimar suas vozes e suas demandas em contraste com os ideais de liberdade e emancipação das feministas brancas (DAVIS, 1983, GONZALEZ, 1984, ANZALDÚA, 1987), o que é até hoje uma questão (EDDO-LODGE, 2017). As reivindicações avançadas por mulheres não-brancas levaram à sistematização de como a opressão opera em interseção (BAIRROS, 1995), levando em conta a sobreposição de sistemas de poder indexados por raça, etnia, gênero e sexualidade para aprimorar a luta feminista por equidade e justiça social, objetivo primordial que não pode ser esquecido (COLLINS, 2017). Isso por si só já evidencia sua vocação antirracista.

Em suma, a visão de mundo acima parte da premissa de que as relações sociais são forjadas por sistemas de poder variados que interagem interseccionalmente na matriz de dominação, na qual o poder hegemônico é exercido de maneira relacional, complexa e contextualizada, inevitavelmente configurando práticas de resistência, construídas no viés contra-hegemônico, dentro e através dos domínios de poder disciplinar, cultural, estrutural e interpessoal (COLLINS, 1990). Entende-se a interseccionalidade como prática investigativa e práxis, o que configura um de seus princípios fundamentais: a sinergia entre práticas epistemológicas e cotidianas na inseparabilidade de teoria e prática (COLLINS, BILGE, 2016). Trazendo essa visão para a produção acadêmica, é crucial entendermos como os sistemas de opressão conformam estrutural e institucionalmente os campos de saber, a academia, a ciência, e subjetivamente as pessoas pesquisadoras. Sob a ótica interseccional, é preciso reforçar a centralidade da questão racial na estruturação das opressões e adotar uma postura combativa a essa estrutura, macro e micropoliticamente. Do contrário, não se pode designar o trabalho como interseccional, mesmo evidenciando alguns marcadores sociais da diferença, como explico abaixo - e nem decolonial, conforme explicado acima.

Considero importante destacar o caráter complexo da investigação que se pretende decolonial e interseccional para driblar a institucionalização acadêmica e o consequente embranquecimento desse olhar (COLLINS, 2017). De uma maneira geral, há alguns pontos observáveis nesse tipo de trabalho, que são determinantes para a experiência do processo investigativo sinergicamente experienciado como práxis, como a atenção ao modus vivendi das pessoas envolvidas com a pesquisa, além do modus operandi epistemológico em si. Primeiramente, é vital entender o caráter constitutivamente relacional dos sistemas de opressão de raça, classe, gênero, sexualidade, idade, habilidade e status de cidadania" (COLLINS, BILGE, 2016, p.195). Ainda que enfatizemos mais um ou outro, ou excluamos alguns aspectos para fins de análise, esses sistemas devem ser entendidos como operando de maneira indissociável. Isso parece óbvio, mas não é. Muitas vezes, trabalhos dessa ordem acabam se utilizando de marcadores sociais da diferença como meros tags (etiquetas) de identificação, estabelecendo nenhuma ou quase nenhuma relação entre os sistemas de opressão que são precipitados na indexicalidade semiótica desses signos, para pegar emprestado o conceito de 
Michael Silverstein $(2003,2006)$ a fim de enfatizar o apontamento que fazem para repertórios culturais, políticos, ideológicos, etc.

Esse olhar deve se juntar a uma visão não-essencialista das identidades como práticas sociais para que eliminemos o risco de reificar certos grupos sociais com base em suas características físicas. O perigo, nesse caso, mora em anunciar marcadores sociais de diferença sem trabalhar com os sistemas de poder que instanciam, porque isso pode significar duas coisas: i) o trabalho não é interseccional, apenas traz características físicas que serão lidas na esteira do senso comum e seus sistemas de coerência (LINDE, 1993), em geral, dentro das formações ideológicas e discursivas da colonialidade; ii) assume-se equivocadamente que esses marcadores operam em um esquema somatório de opressões e não de forma constitutiva e imbricada que molda sujeitos e relações, como de fato ocorre (BAIRROS, 1995), o que traz a complexidade da empreitada à baila, exigindo um trabalho muito mais apurado de investigação do que simplesmente agrupar características-tags para designar pessoas.

Não é raro ver a branquitude acadêmica, especificamente aquela de afiliação a estudos críticos, apresentar suas pesquisas se auto-designando parte de grupos específicos, como mulber branca acadêmica, homem cis bétero branco, etc. explicando que vão trabalhar com grupos minorizados, via de regra, mulheres negras periféricas, bomens negros pobres, autora indígena; etc, listando essas tags sem esmiuçar o que significam social, cultural e ideologicamente, assumindo que essa fala por si só já traz um viés interseccional. Isso, quando muito, aponta para a ideia de que esses marcadores estão postos e, por inferência, as dinâmicas a eles atreladas também. Porém, não é suficiente afirmar que dinâmicas da branquitude cisheteronormativa moderna-colonial-capitalista (CURIEL, 2017) estão postas, afirmando ainda que se dão estruturalmente, se não nos propusermos a lê-las crítica e reflexivamente. Isso reitera um fazer acadêmico dentro dos parâmetros da branquitude que, ciente de como o racismo opera, ainda assim se respalda no artifício da ambiguidade para se eximir da responsabilidade moral sobre essa situação, se conformando em saber mas não agir, em diversas situações, como constata Lia Schucman (2012) em sua tese. Não basta anunciar que tipo de pessoas estão em contato na investigação se isso não significa entender os marcadores sociais da diferença que as tipificam e qual o impacto disso nas dinâmicas sociais, amplas e situadas, tanto da situação observada quanto na pesquisa em si.

De uma maneira geral, trabalhar com parâmetros decoloniais e interseccionais é complexo porque as relações sociais são complexas e a conjugação de saberes múltiplos, institucionalizados ou não, é igualmente complexa. Ainda mais nos estudos críticos da linguagem, em que os marcadores sociais de diferença devem ser analisados em conexão a outros não a priori, mas na medida em que se mostram relevantes nos dados. Por isso é tão importante o preparo da pessoa que analisa esses dados: não há como antecipar, em uma pesquisa em Linguística Aplicada de fato indisciplinar (MOITA LOPES et al, 2006, 2013) e crítica (PENNYCOOK, 2008), quais construtos deverão ser acionados no momento da análise. Falar simultaneamente sobre raça, gênero, sexualidade, classe social, e outros, do ponto de vista contra-hegemônico, compondo a luta por justiça social, como deve ser premissa de trabalhos com essa dupla inclinação, exige bagagem intelectual sobre colonialidade, racismo, feminismo, heteronormatividade, neoliberalismo, e outros, além de sensibilidade e muito estudo para articular os sistemas que estão sendo mais fortemente relevantes para a coerência argumentativa dos pontos levantados pela pesquisa. Além disso, levando em consideração a premissa da sinergia entre prática investigativa e práxis (COLLINS; BILGE, 2016), como dito antes, é fundamental que a branquitude crítica (CARDOSO, 2017) repense os modos de ser, estar, agir e sentir no/ com o mundo (BORGES, 2017a) que a beneficia em relações assimétricas de poder regidas pelo racismo, tanto dentro da lógica interseccional quanto da decolonial, também no fazer acadêmico. Assim, não basta apenas acesso ao arcabouço teórico: é urgente que analistas se disponham a construir seu próprio processo de letramento racial crítico, nos moldes propostos por Aparecida de Jesus Ferreira (2015), que preconiza processos de reflexividade crítica com foco em narrativas autobiográficas para traçar entendimentos acerca dos impactos do racismo em todas as esferas de atuação dos sujeitos raciais, por exemplo. Ou outro, desde que realizem o comprometimento com seus próprios processos de desaprendizagem (FABRÍCIO, 2006), se há alguma ambição de ler o mundo por essas lentes.

Nessas bases, uma Linguística Aplicada que se construa de forma crítica, que responda à sua vocação decolonial e interseccional, compondo uma espistemologia antirracista que centralize questões raciais, é urgente. Por isso, discuto a seguir os desafios de pensar a relação entre branquitude e a área, antes de me ater à performatividade racial branca. 


\section{BRANQUITUDE E LINGUÍSTICA APLICADA CRÍTICA}

Ao pensar a branquitude, corroboro com Leite (2020, p.13) no seu entendimento como "um conceito elaborado a partir de um discurso ético, criado para desvelar certos processos e relações estruturais de dominação, para desmascarar a face oculta do colonialismo, como um operador sub-reptício de naturalização do branco e para transformá-lo em ideal e em universal", sem qualquer paralelo, além do sufixo, com negritude, conceito "tecido por um discurso êmico, para realçar sentidos de pertença e orgulho negro que o colonialismo destroçou, enquanto se elevou como voz regenerativa e em busca de afirmação identitária" (LEITE, 2020, p.13). Assim, o termo branquitude é utilizado para delinear o conjunto de práticas sociais, discursivas, identitárias, inclusive, mas não somente, performadas pelo povo branco e sua performatividade racial constituída material e simbolicamente, nas dimensões estrutural e ideológica do racismo. Ou seja, a branquitude é aquilo que opera em múltiplas dimensões, como parte beneficiária da maquinaria do necropoder capitalista, entendida a constituição tripartite da modernidade-colonialidade-capitalismo (CURIEL, 2017), em que a raça é ficção e expoente do racismo como tecnologia (MBEMBE, 2018). Nesse cenário, branquitude é necessariamente parte da construção ideológica da supremacia branca (ALMEIDA, 2018), que tem na invenção do Branco como o sujeito universal, lido como a própria - e única! - encarnação do humano, no "moralmente, espiritualmente indefensável" projeto civilizatório da modernidade europeia (CÉSAIRE, 1978, p.14).

Isso é relevante pois ajuda a entender as peculiaridades da conformação brasileira de raça e racismo, no sentido de que a branquitude, como posição social de uma coletividade branca e como prática social, portanto, tem implicações diretas, simbólicas e materiais, nos desdobramentos da necropolítica eugenista implementada pelo Estado brasileiro e o aniquilamento da identidade negra em prol da identidade nacional pelos processos de mestiçagem (MUNANGA, 2004). A branquitude acadêmica brasileira, principalmente, opera tanto como beneficiária quanto promotora dessas práticas que nos deram o abjeto mito da democracia racial, ao mesmo tempo em que impulsionaram a ideologia do branqueamento, ambos determinantes na manutenção da ordem estruturalmente racista vigente até os dias de hoje, que sustenta o status quo desigual da hierarquia racial no Brasil em todas as esferas: interpessoal, institucional e estrutural (CARONE; BENTO et al 2014, MULLER ; CARDOSO et al, 2017, ALMEIDA, 2018, CONCEIÇÃO, 2020).

Sob esses termos, olhar para a branquitude na Linguística Aplicada Crítica significa tentar responder de forma contundente às demandas por justiça social que a área acertadamente se propõe a levar adiante, em consonância com sua vocação indisciplinar, anti-hegemônica, mestiça, híbrida, ideológica, crítica, transgressiva (MOITA LOPES et al, 2006, 2013) e, nas palavras de Pennycook (2008, p.170), atenta "às interrelações entre (adaptando Janks, 2000) o domínio (os efeitos contingentes e contextuais do poder), a disparidade (o acesso desigual aos bens materiais e culturais), a diferença (a estruturação e o engajamento com a diversidade) e o desejo (as operações de ideologia, agência e identidade)". Assim, pensar em branquitude é decisivo para que as ambições da área não virem mera pretensão ou retórica, por inúmeras razões das quais destaco duas. Primeiro, por compreender que o campo não está fora da matriz de dominação e é, assim, suscetível às mazelas dos domínios do poder disciplinar, cultural, estrutural e interpessoal (COLLINS, 1990), no contexto da colonialidade de poder/ser/saber (CURIEL, 2017). E isso implica que as práticas investigativas da área estão necessariamente marcadas por assimetrias de poder também relativas a questões raciais e coloniais. Segundo, porque na produção epistemológica do campo nos moldes que trago aqui, sob o entendimento da pesquisa como locus de auto-reflexividade e produção de sentidos em si mesma (DE FINA, 2015), as performatividades de raça em jogo nesse processo são indubitavelmente chave fundamental para uma melhor leitura qualitativa-interpretativa das interações que se dão no processo investigativo e na circulação do conhecimento após a pesquisa.

Nesse contexto, ressalto a importância, então, de pensar as questões raciais sem o vício da fixação pelo negrotema em oposição ao negro-vida, de que Guerreiro Ramos (1995) fala ao apontar a inclinação das ciências sociais, transdisciplinariamente relevantes, ao se debruçar em como as questões raciais acometem o povo negro, ignorando a racialização do povo branco. Esse movimento impede que enxerguemos a branquitude em sua conexão direta com o poder e sua distribuição assimétrica na organização das relações sociais macro e micropolíticas. A questão é que, como polo beneficiado pelo racismo estrutural que, como alerta Silvio Almeida (2018, p.16), "fornece o sentido, a lógica e a tecnologia para a reprodução das formas de desigualdade e violência que moldam a vida social contemporânea", o grupo social branco precisa ser tematizado. 
É nessa toada que defendo que pensemos em branquitude na área, justificada na esteira do que traz Melo $(2019$, p.3) ao dizer que "é possível nos questionar e trazer 'raça' - seus efeitos performativos e corporais - em nossas pesquisas sobre práticas sociais e linguísticas" e, acima de tudo, necessário um olhar atento às performances que, independente do anseio por subversão, são contingenciadas por questões interseccionais e coloniais de poder em que o racismo é determinante. Para a autora, ao fazer pesquisas sob essa ótica, "é importante mencionar que tal abordagem deve lidar com um micro-contexto, entrelaçado com os aspectos históricos e sociais, com todos estes construídos por e em linguagem, cujos efeitos discursivos afetam de fato os corpos" (MELO, 2019, p.2), o que se sustenta ainda mais na produção de saberes situados (HARAWAY, 1988), que costuma reger os trabalhos feitos por linguistas aplicades, aplicadas e aplicados.

Nessa linha de pensamento, advogo por um olhar racializado e racializante para as investigações e, portanto, para os sujeitos envolvidos no processo, em especial o contingente branco, cujas representação e representatividade ainda superam em muito o contingente de pessoas negras e indígenas na academia, pensando em quem mais sofre na pele, literalmente, a desigualdade social operacionalizada pelo racismo no Brasil. Por isso, proponho pensar o papel da branquitude crítica, parte majoritária do grupo social branco que diz não acreditar na supremacia branca (CARDOSO, 2017), na promoção de uma epistemologia antirracista que molde uma Linguística Aplicada que se desenha crítica, capaz de lidar com o tema do privilégio branco na academia sem tergiversar. É preciso ciência de que a racialização dos debates é tensa, porém necessária, se quisermos, de fato, coadunar esforços contra-hegemônicos em "coalizão", nos moldes propostos pelo poeta e filósofo Fred Moten (HARNEY, MOTEN, 2013), para então focar no "em-comum" que nos liga "em um só mundo", como sugere Mbembe (2018, epílogo).

Em suas próprias palavras, direcionadas a pessoas brancas em entrevista, Moten defende que a coalizão só se dará na percepção de que não há necessidade de "ajuda" à ninguém, por parte de quem quer que seja, mas há, sim, uma real necessidade de mudança de paradigma, por meio do reconhecimento de que "está uma merda pra você [branco], da mesma forma que está uma merda para nós [negros]" e que tudo o que precisamos é que "você [branco] reconheça que essa merda está matando você também, mesmo que muito mais suavemente" (HARNEY; MOTEN, 2013, p.141). Considero esse um ponto importante e insisto em trazer essas palavras chulas na tradução ipsis litteris para o português por carregarem uma carga avaliativa necessária para o impacto do que ele diz em relação ao papel de pessoas brancas nesse processo de desmantelamento dos sistemas de opressão.

Com isso em mente, adentro o tema da branquitude, com foco especial para a relação entre branquitude crítica (CARDOSO, 2017) e performatividade racial branca, a fim de estabelecer uma reflexão crítica sobre o silêncio performativo e, posteriormente, escuta ativa e auto-escuta.

\section{BRANQUITUDE CRÍTICA ACADÊMICA, PERFORMATIVIDADE RACIAL BRANCA E O SILÊNCIO PERFORMATIVO}

Primeiramente, deve-se notar que onde abordamos branquitude, abordamos também racismo e privilégio, pois são construtos mutuamente constitutivos. Branquitude, portanto, é um conceito relacional, complexo e deve ser abordado em contexto, explicitando sempre as nuances a que se refere. Neste trabalho, me refiro à branquitude como um conjunto de práticas raciais brancas definidas por Bento (2002, p.5) como:

a racialidade do branco, configurando uma visão de mundo, um posicionamento de vantagens calcado no silêncio e omissão (diante do racismo) por um lado, e por outro, na prática discriminatória sistemática com vistas a conseguir e manter situações de privilégio que impregna a ação e o discurso; e que justifica/ mantém/ reproduz as desigualdades raciais no trabalho.

Replicando essa leitura para as relações hierarquizadas do meio acadêmico, apesar de algumas particularidades, é possível observar dinâmicas similares, o que também é abordado por Cida Bento (2002, p.46), quando diz que "na questão racial brasileira, não é coincidência o fato de que os estudos se refiram ao 'problema do negro brasileiro', sendo portanto sempre unilaterais". Se alinhando a Guerreiro Ramos (1995), ressalta que os estudos não abordam o branco, nem "a herança branca da escravidão, nem tampouco a interferência da branquitude como uma guardiã silenciosa de privilégios" (BENTO, 2002, p.46). Como ela sinaliza, o silêncio é ponto de atenção na performatividade da branquitude porque é performativo de racismo, na complacência do pacto narcísico (BENTO, 2002), entendido como a cumplicidade branca dissimulada que garante privilégios.

O que Cida Bento (2002) traz é fundamental para esta discussão por tocar em pontos importantes: há, de fato, a não racialização de pessoas brancas e suas práticas no meio acadêmico e a dificuldade do grupo social branco de 
se reconhecer enquanto coletividade, mimetizando o ideal neutro/universal europeu em terra brasilis. Mesmo os que se dizem dispostos a se envolver em práticas epistemológicas ditas críticas, se embolam no emaranhado de práticas deslegitimadoras, como o silêncio branco. Nessa leitura, a coletividade branca acadêmica se caracteriza por não se racializar e por se calar perante os privilégios que lhes são garantidos sistematicamente pela discriminação simbólica e material de pessoas negras no espaço da produção de saberes.

Reforçando o olhar de Bento (2002), em seu livro Branquitude: dilemas Raciais Brasileiros, lançado pela Editora Papéis Selvagens em agosto de 2020, William Luiz da Conceição dá um panorama mais amplo dos estudos da área e resume o conceito de forma simultaneamente concisa e complexa. Para o autor $(2020$, p.23):

os estudos contemporâneos da branquitude têm convencionado concebê-la como fenômeno histórico, de caráter interseccional e relacional em sociedades marcadas por desigualdades raciais e sociais advindas do colonialismo ou do imperialismo (Frankenberg, 1999, 2004) [e que a] branquitude seria, ainda, um lugar estrutural de vantagem e de privilégios "raciais" baseados em práticas e identidades culturais, não necessariamente marcadas ou fixas, mas nas quais a brancura é estabelecida como valor simbólico e material. Nesse lugar, poderíamos observar a brancura agir por meio das e nas relações de poder, produzindo dessa forma violências sociais e epistemológicas permanentes (Frankenberg, 1999, 2004; Crapanzano, 1985; Schucman, 2012, 2014; Conceição, 2014, 2017).

A esse desenho do tema, o intelectual complementa, atentando à sua invisibilização nas ciências humanas e sua reformulação nas humanidades, que "o 'branco' deveria ser inserido como irradiador do racismo e parte constituinte das desiguais relações raciais - aflorando como tema e problemática enquanto emergência de estudo" (CONCEIÇÃO, 2020, p.24), trazendo o branco como objeto de investigação e clamando pela ampliação dos estudos sobre o branco, a brancura e a branquitude ao longo de todo o livro, no qual também situa historicamente a branquitude no Brasil. Complementarmente, ainda que o ponto deste trabalho não seja especificamente promover a branquitude como campo específico, faço coro à necessidade de centralizar a racialidade branca para fins de escrutínio das relações de poder que conformam pesquisas acadêmicas em geral, com o objetivo de promover uma epistemologia antirracista.

Com isso em mente, em contraponto ao conceito de branquitude como o conjunto de práticas sociais raciais hegemônicas e, portanto, brancas, nos moldes descritos acima, utilizo o termo branquitude crítica de Cardoso (2017) para me referir ao grupo social branco em si. Segundo o autor, o termo é usado para delinear a maior parte desse grupo, que não é abertamente racista, em contraponto à branquitude acrítica, que destila seu veneno supremacista, convencida de sua suposta superioridade. Para ele, a branquitude crítica é "o branco de maneira geral", que "desaprova o racismo publicamente", mas de quem é "difícil captar a desaprovação ao racismo no espaço privado" (CARDOSO, 2017, p.36). Agora, mais importante que isso, a branquitude crítica "não critica de forma geral o privilégio branco", "vive sob o princípio da iguladade, em tese", "ama, convive, 'tolera', 'suporta', convive hipocritamente com o Outro", "não prega o ódio racial" e é "sincera ou hipócrita na sua concepção relativa ao negro" (CARDOSO, 2017, p.37). Essa segunda lista de características muito interessa aqui, uma vez que a incapacidade de enxergar seu privilégio e a abstração de relações igualitárias em detrimento da prática, aliadas ao convívio pacífico com pessoas negras, a quem a branquitude crítica dedica ora sinceridade, ora hipocrisia, define em alto grau o comportamento do corpo pesquisador branco.

Apesar da desaprovação pública do racismo e do engajamento na luta por justiça social, inclusive com pesquisas alegadamente interseccionais ou decoloniais, recorrentemente a branquitude crítica que atua com teorias críticas na academia, sequer aborda a temática racial. Ainda assim, se julga uma espécie de subgrupo, a branquitude crítica crítica mesmo, se colocando como acima de qualquer suspeita quando o assunto é racismo, assumindo que um viés contra-hegemônico já inclui o pressuposto de uma posição antirracista por parte dos sujeitos envolvidos. Na crença equivocada da possibilidade de um antirracismo por default da área, se declaram antirracistas na certeza de que essa adesão é atestado de reflexividade crítica nesse quesito, o que não se sustenta na prática. Ao contrário, por se entenderem já suficientemente engajadas simplesmente por estarem do lado certo da luta, essa presunção acaba por afastar pessoas que poderiam potencialmente se envolver em processos de letramento racial crítico (FERREIRA, 2015), por exemplo. O ponto é que, apesar de haver nuances nos graus de letramento racial performados por pessoas brancas, a régua para medir o racismo não deve ser aferida a priori, como se a performatividade discursiva dessas declarações se desse à revelia da citacionalidade dos atos performativos (BUTLER, 2014), pensando na articulação micro-macro via linguagem e discurso.

Nesses termos, independente do quão conscientes somos das mazelas do racismo, do ponto de vista das performances discursivas, sempre contingenciadas estruturalmente e interpeladas por relações assimétricas de poder, é notória a maior importância dos efeitos em relação à intenção. Assim, um olhar performativo para a racialidade branca 
implica especial atenção aos efeitos das práticas sociais, discursivas e identitárias que performamos, principalmente se supostamente antirracistas, pois mesmo que encerrem uma intenção genuinamente contra-hegemônica, elas se desdobram socialmente tanto como potência subversiva quanto reificadora de racismo e branquitude, a depender das construções sociossemióticas interacionalmente construídas. Assim, é preciso notar que o grau de aferição de qualquer asserção de antirracismo será atestado somente a partir do efeito da co-construção interacional das performances a ele atrelados ou não. Além disso, é preciso levar em consideração que, à revelia da intenção individual da branquitude crítica (CARDOSO, 2017), a branquitude como prática social é muitas vezes o próprio racismo, como alerta Tatiana Nascimento (2019), e que pessoas brancas são sempre beneficiárias da estrutura racista. Por isso, infelizmente, via de regra o papel de sujeitos brancos que se lêem antirracistas na perpetuação do racismo é preponderante, à revelia de suas intenções, caindo por terra a distinção e a deferência que o grupo branco que se entende como crítico mesmo ousa reclamar ${ }^{1}$.

De todo modo, isso não quer dizer que não existam práticas antirracistas, somente que elas são configuradas performativamente e que não existem pessoas brancas cujas performances não tenham no racismo uma das estruturas rígidas que contingenciam sua performatividade, ainda que agentivamente passíveis de subversão na citacionalidade de nossos atos performativos (BUTLER, 2004). O paradoxo, no entanto, é que pessoas brancas antirracistas não são subversivas, ainda que empenhadas na subversão, porque não é possível o poder hegemônico ser contra-hegemônico. Assim, pessoas brancas podem agir de maneira subversiva, se e somente se os efeitos do que fazem forem contrahegemônicos. Não há subversão por default, pois as intenções do sujeito branco são irrelevantes perante os efeitos e o racismo estrutural e estruturante opera à revelia dessas intenções. No caso, é possível que em embates contrahegemônicos o poder hegemônico ceda, mude, se transforme e, por isso, a participação de sujeitos construídos hegemonicamente em sua auto-desconstrução é fundamental. Aliás, esse é o foco: a busca por subversão da estrutura racista como resultado de processos socialmente construídos de desconstrução do Branco enquanto poder hegemônico, por si mesmo e pelos outros, como reitero ao falar de "estudo" (MOTEN; HARNEY, 2013, HARNEY, 2018) e "sentir crítico" (BORGES, 2017a, 2017b).

Defendo esse ponto e insisto em situar nós, brancos, brancas e branques, distantes da construção do branco subversivo, essa impossibilidade ontológica, porque é muito recorrente no imaginário da branquitude crítica (CARDOSO, 2017) em espaços progressistas. Ali, práticas racistas são reiteradas sob o manto da subversão por default que ambientes de militância ou áreas de estudos críticos na academia carregam, configurando uma prática absolutamente contraproducente. Sujeitos que gozam do poder hegemônico branco que querem sagrar-se contra-hegemônicos por declaração, quase que à revelia de ações antirracistas concretas, esperam gozar de um crédito que não tem e promovem um ambiente de insegurança ainda maior para pessoas negras devido ao trauma do racismo cotidiano (KILOMBA, 2020), impedindo a solidariedade ao invés de reforçá-la. É fácil de entender a importância estratégica de declarações de adesão à luta antirracista, o que deve ser mantido, mas é primordial lidar com a questão racial da branquitude para além da declaração, das hasbtags, da estética. Isso objetiva garantir que os efeitos performativos das práticas raciais da coletividade branca que se pretende antirracista não sejam de escamotear e alimentar, ainda que não intencionalmente, "narrativas que tentam desalojar os corpos negros" e que reificam discursos de "desumanização, objetivação, abjeção, inferioridade, desvalorização e precarização" já tão violentamente presentes na vida de pessoas negras, como constata Glenda Valim de Melo (2019, p.872) em estudo². De todo modo, compreendo que a impossibilidade de ver-se como subversivo é um grande golpe na ilusão de quem constrói suas práticas identitárias em torno do imaginário do aliado nessa luta, mas que, "branco Drácula" (CARDOSO, 2017), sequer se enxerga ainda. Porém, é preciso superar isso, superarmos a nós mesmos, mesmas e mesmes, lembrando que não somos o centro do mundo e agindo de acordo. Essa constatação deve servir, portanto, para mover pessoas brancas de ambição antirracista para além da declaração auto-elogiosa de baixo grau de performatividade para atos performativos mais concretos, menos silenciosos.

Vale ressaltar que o racismo é um sistema de poder estrutural (ALMEIDA, 2018) que atravessa práticas sociais, discursivas e identitárias, e todos, todas e todes têm experiência com suas mazelas, havendo muita oportunidade de demonstração de engajamento que não seja uma declaração egóica. No entanto, entre nós, não discutimos as

1. Essa observação esbarra na discussão acerca da diferença entre branquidade e branquitude, a qual não adentro neste trabalho, mas pode ser observada no livro organizado por Tatiana Muller e Lourenço Cardoso (2017).

2. Em seu estudo, Melo (2019) versa sobre a trajetória textual de anúncios relativos ao tráfico de escravos em um jornal impresso do século XIX e em um site de compra e vendas do século XXI. Sem entrar no mérito da excelente análise da indexicalidade semiótica do texto multimodal em questão, é relevante pontuar que o material pode ser classificado como uma instanciação de performance de raça da branquitude acrítica, relacionalmente construída na violência contra o povo negro discursiva e textualmente ali materializada. 
práticas racistas, apenas as reiteramos em cumplicidade e segredo (CARDOSO, 2017) e, em público, nos declaramos antirracistas com a mesma facilidade com que nos silenciamos sobre e perante o racismo. A questão é que, em geral, a branquitude crítica (CARDOSO, 2017) não quer falar de racismo, ela quer falar de sua luta, suas tristezas, suas angústias com a situação de pessoas negras, alegando muitas vezes que não tem experiência para se aprofundar, que por isso vai só ouvir. Só que não há uma pessoa em contato com o mundo moderno-ocidental-capitalista em que vivemos que não tenha experiência com o racismo. A questão é de que posição social interseccionalmente constituída o sujeito racial apreende tal experiência: como privilegiado pela assimetria de poder ou prejudicado por ela. Essa, sim, deveria ser a prioridade de fala branca sobre o racismo, sua posição de privilégio, não a asserção do seu antirracismo, à espera de certificação de aliado.

$\mathrm{Na}$ academia, que não está dissociada da vida, a situação se repete: a branquitude crítica acadêmica também não quer falar sobre racismo, pensá-lo do ponto de vista branco, sua perspectiva, buscando entender o favorecimento que o sistema confere às pessoas brancas em detrimento de pessoas negras e indígenas, principalmente. Mesmo quando pensa na questão racial, a academia branca, inclusive a que se diz crítica, quer, na realidade, falar ainda sobre o problema do negro, como nos lembra Guerreiro Ramos (1995), sobre a mulher negra, a negritude, as particularidades da população negra, da estética negra, das experiências do Negro, a circulação de discursos sobre a negritude, as performances raciais negras, as desigualdades que acometem o povo negro, sua vulnerabilidade social, a escravidão, a ancestralidade Africana. E isso, na maior parte das vezes, de maneira não-relacional, ao invés de falar sobre o problema do branco, sobre a mulher branca, a loucura do orgulho branco, as particularidades da população branca, da estética branca, das experiências do Branco, a circulação de discursos da própria branquitude, as performances raciais brancas, o privilégio da brancura que protege igualmente branquitude crítica e acrítica (CARDOSO, 2017), sua mobilidade social hereditária, sua ancestralidade violenta, etc. E, ainda, se ofende quando dizem que dessa forma não é possível seguir se colocando como antirracista.

Por fim, por tudo dito acima, cabe a defesa assertiva da auto-racialização do olhar analítico da branquitude crítica acadêmica na Linguística Aplicada Indisciplinar e Crítica, com lentes simultaneamente decolonial (CURIEL, 2017) e interseccional (COLLINS, 1990) para a promoção de um fazer epistemológico antirracista, construído pelo "estudo" (HARNEY, 2018) e pela (auto)reflexão (auto)crítica em prol de um sentir crítico (BORGES, 2017a, 2017b), como concluo a seguir.

\section{FECHANDO EM ABERTO: ESTUDO, ESCUTA E SENTIR CRÍTICO}

No contexto de uma academia cujas demandas de produção são orientadas pela lógica da instituição moderna-colonial-capitalista (CURIEL, 2017), há muito pouco espaço para respiro, para a fluidez dos pensamentos, sentimentos e sentidos necessários para a dedicação ao estudo enquanto prática social. Em linhas gerais, entendo o estudo como um conjunto de práticas que visa construir entendimentos do mundo à nossa volta, espaço-tempo de percepção compreensiva, de afetos revolucionários e de experiência coletiva na construção de novos mundos possíveis. Em consonância com isso, Harney (2018, on-line) descreve o estudo como "uma espécie de encontro de recursos", de material, de pessoas, de espaço, de tempo, de sentimentos, de sentidos, de relação em rede, que propiciam o "auto-desenvolvimento coletivo, uma ideia de que a razão pela qual nos juntamos é tentar compartilhar e desenvolver nosso senso de ideias, e história, e filosofia, etc. etc. etc." (HARNEY, 2018, on-line). Pensado a partir da recusa da "academia da miséria" (HARNEY; MOTEN, 2013, p.117), Fred Moten pensa nessa academia enxergando a universidade como tempo-espaço de "naturalização da infelicidade", onde "o prazer é suspeito, não confiável" (HARNEY, MOTEN, 2013, p.117), onde opera em subversão qualquer intelectual que se envolva genuinamente com o que faz e, portanto, com prazer. Nessa lógica, acreditar que é possível mudar o mundo, por exemplo, pode ser visto como algo que não é profissional (HARNEY, MOTEN, 2013, p.30), que não está de acordo, que está fora do lugar, como é recorrente na produção de saberes da intelectualidade negra, sempre confrontada sobre seu ativismo e sua impertinência à academia (COLLINS, 1990). O estudo é "um modo de pensar com os outros, separado do pensamento que a instituição exige de você" de uma maneira palpavelmente "revolucionária" (HALBERSTAM, 2013, p.11), aquilo que se faz à revelia, no espaço-tempo dos abaixo-comuns; os confins das universidades e da vida que abrigam sujeitos múltiplos que performam resistência e reexistência essencialmente pelo movimento fugitivo da antigovernança da pretitude (HARNEY; MOTEN, 2013). 
Esses espaços-tempo são abertos, permeáveis, penetráveis, pois ao mesmo tempo que do lado de dentro, são impossíveis de serem circunscritos na lógica do sistema (HARNEY, MOTEN, 2013). Assim, cientes da sua inadequação e do quão indesejáveis são perante a ordem colonial e colonizada da universidade, essa ala subversiva, moldada pelo suposto amadorismo, se move à revelia dele, mas nas entranhas dele, pois sabe que "não dá para negar que a universidade é lugar de refúgio" ao mesmo tempo em que "não dá para aceitar que a universidade seja um lugar de iluminamento ${ }^{\prime \prime}$. Nesse movimento fugitivo, então, em coalizão, os sujeitos se propõe a desenvolver uma espécie de relação "criminosa" com ela: "roubando" o que acha que deve, se juntando à "colônia de refugiados", "estando dentro mas não sendo dela" (HARNEY; MOTEN, p.26). Nessa linha de atuação, uma epistemologia antirracista encontra terreno fértil para se desenhar, na esteira das performances dos abaixo-comuns, nas performances da pretitude e da negritude, mas também em coalizão, focando na destruição dos sistemas de governança da branquitude (MOTEN; HARNEY, 2013), em um comportamento subversivo cujo princípio básico está no encontro de intelectuais com suas motivações mais genuínas, contra-hegemonicamente orientadas.

No contexto da Linguística Aplicada Indisciplinar e Crítica, isso deve significar uma sede insaciável por transformação social. Nessa linha, pensar em epistemologia antirracista é indispensável e demanda convocar a branquitude crítica interessada em agir em coalizão para estudar novas formas de vida, novos mundos, novas humanidades, pensando branquitude, racismo e questões raciais em processos crítico-reflexivos à revelia do sistema, ou seja, sem crédito, sem condecoração. Por isso, o estudo, visto dessa forma, deve se dar subjacente a tudo que fazemos, mobilizando nossos modos de ser, estar, agir e sentir no/ com o mundo (BORGES, 2017) em prol da criação de perspectivas outras. A importância disso está em incluir a própria área como lugar carente de equidade e passível de transformação social, indo além do anúncio de mera intenção ou vocação à priori, nos dispondo a abraçar um longo processo transformativo, focado na micropolítica coletiva do cotidiano, em todos os domínios da vida. Nos espaços-tempo dentro e fora da academia, isso deve nos mover para ampliar o desenho do fazer epistemológico para simplesmente "estudo", nos moldes que resumem Moten e Harney (2013), subversivamente prazeroso. Esse prazer vem da possibilidade de se construir um novo mundo e, nesse processo, em andamento, produzir também gramáticas para sua leitura, formulando entendimentos na medida em que é construído. Isso é estudo. Isso deveria ser produção acadêmica.

Nesse contexto, mobilizado nos e pelos processos (auto)críticos-(auto)reflexivos configurados em movimento, cabe pensar no sentir crítico (BORGES, 2017a, 2017b), que foca no afeto como força motriz da busca por justiça social em relação de complementaridade e dependência para com práticas de letramento crítico. Centralizando a performatividade afetiva (AHMED, 2004) para fins de mudanças genuinamente constituídas, propõe um convite para irmos além do foco cognitivo, que preza pelo ato de pensar criticamente a partir da concatenação coerente de ideias, e do foco nas práticas, que implica em agir politicamente, borrando o binarismo insustentável razão/emoção, pensar/sentir. Sob essa ótica, somos corpos sensíveis pensantes, de pensamentos sensivelmente corporificados e sensibilidades cognitivamente vividas, com possibilidades infinitas para além desse (sistema-)mundo.

Nessa lógica de completude, o sentir crítico é uma espécie de "devir de sensibilidade" (BORGES; 2017b, p.9) em que e por meio do qual "impressões" (AHMED, 2004), que consistem no "todo indissociável" de "sensação corporal, emoção e pensamento" "cujos aspectos não podem ser experimentados como domínios distintos da experiência humana" (AHMED, 2004, p.6), fluem performativamente em afetos, a partir de processos de (auto)criticidade e (auto)reflexividade que podem transformar modos de ser, estar, agir e sentir no/ com o mundo (BORGES, 2017a), sempre em um horizonte de justiça social. O sentir crítico é, portanto, fio condutor de modos de viver que configuram em si mesmos espaço-tempos semoventes de transformação micropolítica coletiva, posto que construídos socialmente via performatividade afetiva, em fluxo, em movimento, para fins de comunidade.

Retomando "o estudo" (MOTEN, HARNEY, 2013, HARNEY, 2018) como um movimento vivo, um encontro de subjetividades que instiga uma relação curiosa entre vida e fazer epistemológico, em que teorizar não é meta, mas processo subversivo de reflexividade crítica apreciado em si mesmo, acredito em seu potencial para aguçar nosso sentir crítico, conforme descrito acima. Como expressão da vontade comunitária de traçar entendimentos acerca do mundo, o estudo atende à demanda por conexão "com outros seres humanos, democraticamente, em comunidade"

3. Tradução livre minha para "enlightenment" que se refere a processos de entendimento, de aprendizado, de educação, de consciência com um teor de clarividência, iluminação de ideias, insight, mas também é utilizado em referência ao Iluminismo, período histórico referente ao movimento intelectual europeu que centraliza a razão e o individualismo em detrimento de todo o resto da modernidade-colonialidadecapitalismo. 
(BORGES, 2017a, p.89). Assim, modos de sentir criticamente são alimentados nas/ pelas performances afetivas agregadas a processos de "sensibilização quanto a questões de sofrimento humano, estigma, ideologia e relações de poder" (BORGES, 2017, p.6). Em um pressuposto de justiça social, reitero, essa dinâmica compõe instâncias micropolíticas contra-hegemônicas que nos traz cíclica e continuamente de volta ao estudo. No contexto da busca por uma epistemologia antirracista para a área da Linguística Aplicada Indisciplinar e Crítica, nos colocar em movimento de estudo em relação às questões raciais, racismo e branquitude significa estar em mobilização afetiva pela transformação social que vislumbramos para a vida, em processos constitutivos do e pelo sentir crítico.

Trazendo isso para o contexto das interações de pesquisa em si como tempo-espaços de co-construção de sentidos (DE FINA, 2015), é possível introduzir a importância da escuta ativa e da escuta de si também como instâncias em que outras performatividades de silêncio que desafiem o racismo são produzidas. Nesse sentido, aliar a esse processo práticas de letramento racial crítico, conforme proposto por Ferreira (2015), ou outras práticas que envolvem (auto)reflexividade crítica com foco em racismo e branquitude, é essencial para garantir que a escuta se traduza em entendimentos condizentes com vontade de subversão e uma auto-escuta produtiva, afetiva e efetivamente transformadora. Esse é um longo processo, que exige envolvimento e atenção sob todos os aspectos: é preciso pensar/agir/sentir criticamente para dar conta de seus desdobramentos.

Nessa linha, pensando mais especificamente nas interpretações qualitativas que fazemos na área e no caráter performativo do silêncio, o efeito antirracista que pode advir de práticas de "escuta ativa, reflexiva, transformativa" (NASCIMENTO, 2019, on-line) coloca o desafio para a branquitude crítica acadêmica de rever suas próprias construções de branquitude, que nublam seu entendimento de mundo, a fazendo crer na importância indubitável de sua fala, via de regra validada na academia cubo-branco.

A escuta ativa, nesse contexto, traz a possibilidade de conter o ímpeto epistemológico autoritário da academia branca, ao propor o ato de ouvir o outro como um processo de conscientização configurado na escuta de mundos (FREIRE, 1995). Extensão disso, a noção de auto-escuta, com base na redefinição de letramento crítico de Lynn Mario Menezes de Souza (2011), vai além. Como forma de apreciar "em toda a sua plenitude a complexidade da relação freireana palavra-mundo" (MENEZES DE SOUZA, 2011, p.132), o autor amplia seus sentidos e defende processos de letramento que foquem na dobra da escuta/leitura do mundo e a escuta/leitura de si enquanto escuta/lê o mundo. O ato de "se ouvir escutando", significa, em poucas palavras, um processo (auto)crítico-reflexivo que visa reconhecer-se no embate interacional entre mundos, de forma relacional. Em suma, é preciso atentar para o nosso mundo, nosso eu-sociohistórico, incluindo aí a posição social que ocupamos, ao mesmo tempo em que refletimos sobre os sentidos construídos com o mundo, em interação, incluindo relações de poder que interseccionalmente atravessam a troca, acima de tudo, atentando para o porquê de escutarmos isso ou aquilo, de uma forma e não de outra, para entender o que nos faz interpretar/sentir as coisas da forma com que interpretamos/sentimos, a fim de imprimir mudanças contra-hegemônicas necessárias.

Por tudo isso, vislumbrando uma epistemologia antirracista para uma Linguística Aplicada efetivamente Crítica, proponho um olhar atento às performatividades afetivas a fim de nos interpelar sobre nossas "impressões" (AHMED, 2004). Esse olhar deve ser construído em movimento de "estudo" (MOTEN, HARNEY, 2013), agregando processos de (auto)letramentos críticos múltiplos, especialmente o letramento racial crítico (FERREIRA, 2015), com ajuda de lentes variadas, a decolonial e a interseccional, por exemplo, a fim de configurar modos de ser, estar, agir e sentir no/com o mundo mais criticamente reflexivos, em prol do sentir crítico também na academia. Isso pode garantir à branquitude crítica acadêmica o escrutínio de si, de suas interpretações enviesadas pela branquitude, de seu racismo. Afinal, o racismo é uma problemática branca (KILOMBA, 2016), nunca é demais frisar.

\section{REFERÊNCIAS}

AHMED, S. (2004). The Cultural Politics of Emotion. Edinburgh University Press.

ALMEIDA, S. (2018). Racismo Estrutural. Belo Horizonte: Letramento: Justificando.

ANZALDÚA, G.. (1987). Making Face / Making Soul Haciendo Caras. Creative and Critical Perspectives by Women of Color. San Francisco: Aunt Lute. 
BAIRROS, L. (1995). Nossos feminismos revisitados. Revista Estudos Feministas, 3 (2), pp. 458-463.

BENTO, M. A. S.(2002). Branqueamento e Branquitude no Brasil. In: CARONE, I.; BENTO, M. A. S.(Org). Psicologia social do racismo - estudos sobre branquitude e branqueamento no Brasil. Petrópolis, RJ: Vozes.

BORGES, T. R. S. (2017a). Por um sentir crítico: um olhar feminista interseccional sobre a socioconstrução de identidades sociais de gênero, raça/etnia e classe de professoras de línguas. Rio de Janeiro - Dissertação (Mestrado). Programa de Pós-Graduação em Letras da Pontifícia Universidade Católica do Rio de Janeiro, PUC-Rio. Disponível em: http://tiny. cc/TRSBorges2017 Acesso: 20.07.2021.

BORGES, T. R. S. (2017b). "Pelo amadurecimento de um "sentir crítico": entendendo a socioconstrução de identidade de uma professora negra e seus atravessamentos interseccionais. Revista Veredas. Atemática. PPG Linguística/ UFJF. Juiz de Fora, Vol. 21 no.2. Disponível em: http://tiny.cc/SentirCriticoVEREDAS Acesso: 20.07.2021.

BUTLER, J. (1990). Gender trouble: feminism and the subversion of identity. New York: Routledge.

BUTLER, J. (2004). Undoing Gender. New York/London: Routledge.

BUTLER, J. (2014). When gesture becomes event. Theater Performance Philosopby - International Conference: Crossings and Transfers in Contemporary Anglo-American Thought. Disponível em: https://goo.gl/UUjwKo Acesso: 20.07.2021.

CARNEIRO, S. (2005) A Construção do Outro como não-ser como fundamento do ser. Tese de Doutorado em Educação. Área da Filosofia da Educação. Universidade de São Paulo, SP.

CARDOSO, L. (2017). A Branquitude Crítica Revisitada e as Críticas. In: MULLER, T. M. P.; CARDOSO, L. (Orgs.). Branquitude: estudos sobre a identidade branca no Brasil. Curitiba: Appris, 2017.

CARONE, I.; BENTO, M. A. S .(2014). Psicologia Social do Racismo: Estudos sobre a branquitude e branqueamento no Brasil. Petrópolis, RJ: Editora Vozes.

CÉSAIRE, A (1978). Discurso sobre o colonialismo. Lisboa: Sá da Costa.

COLLINS, P. H. (1990). Black feminist thought: knowledge, consciousness, and the politics of empowerment. New York: Routledge.

COLLINS, P. H. (2017). Se perdeu na tradução? Feminismo negro, interseccionalidade e política emancipatória. Revista Parágrafo. 2017. pp.6-17.

COLLINS, P.; BILGE, S. (2016). Intersectionality. Cambridge: Polity Press.

CONCEIÇÃO, W. L. (2020). Branquitude: dilema racial brasileiro. Rio de Janeiro (RJ): Papéis Selvagens, 2020. Disponível em: http:// www.papeisselvagens.com/livros-para-download.html Acesso: 20.07.2021.

CURIEL, O. (2017). Feminismo Decolonial. Prácticas Políticas Transformadoras. Conferencia, 2017. Disponível em: https://www. youtube. $\mathrm{com} /$ watch?v=B0vLlincsg0 Acesso: 20.07.2021.

DAVIS, A. Y .(1983). Women, race and class. New York: Vintage books, 1983.

DE FINA, A. (2015). Narrative and Identities. In: DE FINA, A.; GEORGAKOPOULOU, A. The Handbook of Narrative Analysis. John Wiley \& Sons, Inc. Published. pp. 119-139.

EDDO-LODGE, E. Why I'm no longer talking to white people about race. Bloomsbury Publishing, 2017.

FABRICIO, B. F.. (2006). Linguística Aplicada como espaço de "desaprendizagem": redescrições em curso. In: MOITA LOPES, L. P. (Org.) Por uma linguística Indisciplinar. São Paulo: Parábola Editorial, pp.45-63.

FERREIRA, A. J. Letramento racial crítico através de narrativas autobiográficas: com atividades reflexivas. Ponta Grossa: Editora Estúdio Texto, 2015. 
FREIRE, P. (1995). Pedagogia da Tolerância. Rio de Janeiro/ São Paulo: Paz e Terra. 2020.

GONZALEZ, L. (1984). Racismo e sexismo na cultura brasileira. Revista Ciências Sociais Hoje, Anpocs. pp. 223-244.

HALBERSTAM, J. (2013). The Wild Beyond: With and for the Undercommons. In: HARNEY, S; MOTEN, F. The Undercommons: Fugitive planning and Black Study. Wivenhoe /New York/Port Watson: Minor Compositions.

HARAWAY, D. (1988). Situated Knowledges: The Science Question in Feminism and the Privilege of Partial Perspective. Feminist Studies, Vol. 14, No. 3. Autumn. pp. 575-599.

HARNEY, S. (2018). Stefano Harney on Study. YouTube canal oficial: Stefano Harney. Disponível em: https://www.youtube.com/ watch?v=uJzMi68Cfw0 Acesso: 20.07.2021.

HARNEY, S.; MOTEN, F. (2103). The Undercommons: Fugitive planning and Black Study. Wivenhoe /New York /Port Watson: Minor Compositions, 2013.

KILOMBA, G. (2016). O racismo é uma problemática branca, diz Grada Kilomba. Carta Capital. Disponível em: https://www. cartacapital.com.br/politica/201 co-racismo-e-uma-problematica-branca201d-uma-conversa-com-grada-kilomba/ Acesso: 20.07.2021.

KILOMBA, G. (2019). Exposição Desobediências Poéticas, Pinacoteca, São Paulo. Disponível em: https:// pinacoteca.org.br/en/ programacao/grada-kilomba-poetic-disobediences/Acesso: 20.07.2021.

KILOMBA, G. (2020). Memórias da Plantação. Rio de Janeiro: Cobogó.

LEITE, I. B. (2020) Prefácio: Branquitude: a mais nítida face do racismo no Brasil e no mundo. In: CONCEIÇÃO, W. L. Branquitude: dilema racial brasileiro. Rio de Janeiro (RJ): Papéis Selvagens, pp.13-16.Disponível em: http://www.papeisselvagens.com/ livros-para-download.html Acesso: 20.07.2021.

LIMA, F. (2018). Comunicação pessoal. Aula da disciplina: Bio/Necropoder, no CEFET, Rio de Janeiro.

LINDE, C. (1993). Life stories: The creation of coherence. NY/Oxford: Oxford University Press.

MENEZES DE SOUZA, L. M. (2011) Para uma redefinição de letramento crítico: conflito e produção de significação. In: Maciel, R. F.; Araújo, V. A. (Org.) Formação de professores de Línguas: ampliando perspectivas. Jundiaí: Paco Ed.. pp.128-140.

MBEMBE, A. (2018). A crítica da razão negra. São Paulo: N-1 edições.

MELO, G. C. V. (2019). Slave Trade Ads in the 19th Century: Textual Trajectory, Entextualization and Indexical Orders Mobilized on Contemporary Ads. Rev. Bras. Linguíst. Apl., Ahead of Print.

MOITA LOPES, L. P. (2006) Por uma Linguística Aplicada Indisciplinar. São Paulo: Parábola Editorial.

MOITA LOPES, L. P. (2013). Linguística Aplicada na Modernidade recente. São Paulo: Parábola Editorial.

MULlER, T. M. P.; CARDOSO, L. (Orgs.). (2017). Branquitude: estudos sobre a identidade branca no Brasil. Curitiba: Appris.

MUNANGA, K. (2004). Rediscutindo Mestiçagem no Brasil. Identidade nacional versus identidade negra. Belo Horizonte / São Paulo: Grupo Autêntica.

NASCIMENTO, T. (2019) a branquitude é um lugar de fala. Medium.com Conta oficial: @tatiananascivento Disponível em: shorturl. at/duzV4 Acesso: 20.07.2021.

PENNYCOOK, A. (2008). Critical applied linguistics and language education. In: S. May and N. H. Hornberger (Eds). Encyclopedia of Language and Education, 2nd Ed, v.1. Springer Science \& Business Media LLC. pp. 169-181.

QUIJANO, A. (2010). Colonialidade do poder e classificação social. In: SOUSA SANTOS, B. MENESES, M. P. (Orgs) (2010). Epistemologias do Sul. São Paulo: Cortez. 
RAMOS, A. G. (1995). Introdução à Sociologia Brasileira. Rio de Janeiro: Editora UFRJ.

SCHUCMAN, L. V. (2012). Entre o "encardido", o "branco" e o "branquíssimo": Raça, bierarquia e poder na construção da branquitude paulistana. Tese de Doutorado em Psicologia Social. Instituto de Psicologia, Universidade de São Paulo, SP.

SILVERSTEIN, M. (2003). Indexical order and the dialectics of sociolinguistic life. Language \& Communication, 23, pp. 193-229.

SILVERSTEIN, M. (2006). Pragmatic Indexing. The University of Chicago: Elsevier Ltd.

SOUSA SANTOS, B. MENESES, M. P. (Orgs) (2010). Epistemologias do Sul. São Paulo: Cortez.

Recebido: 30/10/2020

Aceito: 3/3/2021

Publicado: 28/7/2021 